\title{
Serum microRNAs as predictors of risk for non-muscle invasive bladder cancer
}

\author{
Jie Lian ${ }^{1}$, Shu-Hong Lin ${ }^{1}$, Yuanqing Ye ${ }^{1}$, David W. Chang ${ }^{1}$, Maosheng Huang ${ }^{1}$, Colin \\ P. Dinney ${ }^{2}$ and Xifeng $\mathbf{W u}^{1}$ \\ ${ }^{1}$ Department of Epidemiology, The University of Texas MD Anderson Cancer Center, Houston, TX 77030, USA \\ ${ }^{2}$ Department of Urology, The University of Texas MD Anderson Cancer Center, Houston, TX 77030, USA \\ Correspondence to: Xifeng Wu, email: xwu@mdanderson.org
}

Keywords: serum miRNA; biomarker; expression ratio; risk score; non-muscle-invasive bladder cancer

Abbreviations: NMIBC: non-muscle invasive bladder cancer; miRNA: microRNA

Received: May 24, 2017 Accepted: January 13, 2018 Epub: February 12, 2018 Published: March 13, 2018

Copyright: Lian et al. This is an open-access article distributed under the terms of the Creative Commons Attribution License 3.0 (CC BY 3.0), which permits unrestricted use, distribution, and reproduction in any medium, provided the original author and source are credited.

\section{ABSTRACT}

MicroRNAs (miRNAs) are implicated in the development of nearly all cancers and may function as promising biomarkers for early detection, diagnosis and prognosis. We sought to investigate the role of serum miRNAs as potential diagnostic biomarkers or biomarkers of risk for early-stage bladder cancer. First, we profiled global serum miRNAs in a pilot set of 10 non-muscle invasive bladder cancer (NMIBC) cases and 10 healthy controls matched on age, gender and smoking status. Eighty nine stably detectable miRNAs were selected for further testing and quantification by high-throughput Taqman analysis using the Fluidigm BioMark HD System to assess their association with NMIBC risk in both discovery and validation sets totaling 280 cases and 278 controls. We found miR-409-3p and six miRNAs expression ratios were significantly associated with risk of bladder cancer in both discovery and validation sets. Interestingly, we identified expression of $\mathrm{miR}-409-3 p$ and $\mathrm{miR}-342-3 p$ inversely correlated with age and age of onset of NMIBC. A risk score was generated based on the combination of three miRNA ratios (miR-29a-3p/miR-222-3p, miR-150-5p/miR-331-3p, miR-409-3p/miR-423-5p). In dichotomized analysis, we found individuals with high risk score showed increased risk of bladder cancer in the discovery, validation, and combined sets. Pathway enrichment analyses suggested altered miRNAs and cognate target genes are linked to the retinoid acid receptor (RAR) signaling pathway. Overall, these results suggested specific serum miRNA signatures may serve as noninvasive predictors of NMIBC risk. Biological insights underlying bladder cancer development based on the pathway enrichment analysis may reveal novel therapeutic targets for personalized medicine.

\section{INTRODUCTION}

Bladder cancer is the second most common genitourinary malignancy worldwide. In the United States, bladder cancer is the fourth most common cancer in men. The estimate for new cases is 76,960 and for deaths is 16,390 in 2016 [1]. Non-muscle invasive bladder cancer (NMIBC), including stage Ta and T1 and carcinoma in situ (CIS), accounts for $70 \%-80 \%$ of all newly diagnosed bladder cancer cases [2]. When bladder cancer is detected early, the 5-year survival rate is approximately 94\% [3].
Therefore, it is important to identify patients at early stage for improved outcome. The current gold standard for diagnosis of bladder cancer remains white light cystoscopy of bladder coupled with urine cytology [4]. However, cystoscopy is an uncomfortable and costly invasive procedure, while the sensitivity of urine cytology for the detection of early-stage tumors is low as there are typically few cells found in urine [4]. Extensive research has attempted to identify early detection biomarkers, but these assays are either limited with high false positive rate or low sensitivity [5]. These limitations underscore 
the need for novel biomarkers, particularly noninvasive biomarkers in serum or plasma, for early detection or diagnosis of bladder cancer.

Over the last decade, numerous studies have demonstrated the potent pro- and anti-tumorigenic functions of microRNAs (miRNAs), which are a class of small noncoding RNAs that play a central role in the regulation of mRNA expression [6]. MiRNAs are frequently deregulated in bladder cancer and could contribute to bladder cancer development, progression and metastasis [7]. Additional studies have documented the existence of a large number of stable miRNAs in human blood samples with altered levels in cancer patients, which opened up the prospect of using circulating miRNAs as non-invasive cancer biomarkers [8, 9]. For example, serum miR-21 has been identified as a promising biomarker for the early detection and prognosis of colorectal cancer [10]. A miRNA panel consisting of 7 miRNAs provided a high diagnostic accuracy of hepatocellular carcinoma [11] and a five circulating miRNA signature has been identified for the diagnosis of very high-risk prostate cancer [12]. Although a recent study of serum miRNA expression from genome-wide profiling has been conducted for NMIBC [13], the study population involved East Asians and similar studies on Caucasians are not found.

In the present multiphase study, we first performed pilot screening to determine the expression profiles of 754 serum miRNAs using Taqman miRNA arrays in patients with NMIBC and healthy controls from hospital and clinic-derived non-Hispanic Caucasian population. Next, stably detectable miRNAs were selected and simultaneously quantified in two additional discovery and validation sets by high-throughput, multiplex quantitative real-time reverse-transcription PCR (qRT-PCR) analysis in order to evaluate the clinical significance of these miRNAs as potential biomarkers for diagnosis and risk prediction of bladder cancer. In addition, predicted targets of the miRNAs were analyzed in silico to identify enrichment in pathways, yielding possible underlying biological mechanisms for future experimental verification.

\section{RESULTS}

\section{Patient characteristics}

The patient characteristics for 140 NMIBC patients and 139 healthy controls in each discovery and validation set were summarized in Table 1. There were no significant differences in the distribution of age and sex between the discovery and validation sets between cases and controls. A statistically significant higher proportion of ever smokers was observed in cases compared to controls $(P<0.001)$.

\section{Individual association of serum miRNAs with NMIBC risk}

The 89 candidate miRNAs were assessed for serum expression using Fluidigm 96.96 Dynamic Array, a high throughput microfluidic array that enables simultaneous quantification by real-time PCR for 96 individual samples against 96 different miRNAs in a single experiment. After quality control and data cleaning (as described in Materials and Methods), the expression levels of 12 miRNAs were significantly associated with risk of NMIBC in the discovery set using tertiles of the miRNA levels in controls as cutoff points. When the same cutoffs were applied to the validation set, one miRNA, miR-409$3 p$, remained significantly associated with NMIBC with a significant trend for increased risk in the tertiles with reduced expression for both discovery set $(P$ for trend $=$ $0.013)$ and validation set $(P$ for trend $=0.019)$ (Table 2$)$. Pooled analysis indicated that this risk was the highest in the lowest tertile group (adjusted odds ratio [OR] = $2.21 ; 95 \%$ confidence interval $[\mathrm{CI}]=1.40-3.50 ; P=7.19$ $\left.\times 10^{-4}\right)$. Box plots showing the differential serum levels of miR-409-3p in cases and controls in the discovery, validation, and combined sets is shown in Figure 1.

\section{Individual association of serum miRNAs with onset of NMIBC and age of onset}

Patients with early age onset of NMIBC may present distinct genetic and molecular features. To examine whether serum miRNAs may predict age of onset of NMIBC, we analyzed the 89 candidate miRNAs and their association with age of onset of NMIBC in both discovery and validation sets. Only two miRNAs, miR-409-3p and miR-342-3p, showed significant results in both groups. Patients with high level of both miRNAs displayed 1.8fold $\left(\mathrm{HR}=1.83,95 \% \mathrm{CI}, 1.41-2.38, P=2.02 \times 10^{-5}\right)$ and 1.6-fold $(\mathrm{HR}=1.60,95 \% \mathrm{CI}, 1.24-2.05, P=2.05$ $\times 10^{-4}$ ) increased risk of early onset of NMIBC in the combined population, respectively (Table 3 ). Patients with high serum level of these miRNAs have median age of onset of 63 years compared to 68 years for the low level group. Similar findings are found using the tertile analysis (data not shown). To check whether the association of miR-409-3p and miR-342-3p with onset of NMIBC is not confounded by association with age, we assessed the correlation of serum levels of these miRNAs with age of subjects separately in cases and controls. To have sufficient numbers, we combined the discovery and validation groups. We found serum levels of miR-409-3p and $\mathrm{miR}-342-3 \mathrm{p}$ were inversely correlated with age in both cases and controls (Spearman's rho $=-0.28$ to -0.22 , $P<0.001)$ (Supplementary Table 1). 
Table 1: Host characteristics of patients with NMIBC and controls

\begin{tabular}{|c|c|c|c|c|c|c|}
\hline \multirow[b]{2}{*}{ Variables } & \multicolumn{3}{|c|}{ Discovery set } & \multicolumn{3}{|c|}{ Validation set } \\
\hline & $\begin{array}{c}\text { Cases } \\
N=140, N(\%)\end{array}$ & $\begin{array}{c}\text { Controls } \\
N=139, N(\%)\end{array}$ & $P$-value ${ }^{*}$ & $\begin{array}{c}\text { Cases } \\
N=140, N(\%)\end{array}$ & $\begin{array}{c}\text { Controls } \\
N=139, N(\%)\end{array}$ & $P$-value* \\
\hline \multicolumn{7}{|l|}{ Age (y) } \\
\hline Mean (SD) & $64.91(10.87)$ & $65.14(10.17)$ & 0.860 & $64.36(11.04)$ & $64.29(9.92)$ & 0.952 \\
\hline \multicolumn{7}{|l|}{ Pack year** $^{* *}$} \\
\hline Mean (SD) & $38.76(29.48)$ & $26.71(22.51)$ & 0.005 & $38.48(31.02)$ & $33.52(29.66)$ & 0.292 \\
\hline \multicolumn{7}{|l|}{ Sex } \\
\hline Male & $127(90.71)$ & 127 (91.37) & & $120(85.71)$ & 118 (84.89) & \\
\hline Female & $13(9.29)$ & $12(8.63)$ & 0.849 & $20(14.29)$ & $21(15.11)$ & 0.846 \\
\hline \multicolumn{7}{|l|}{ Smoker } \\
\hline Ever & $96(69.06)$ & $68(49.28)$ & & $102(73.38)$ & $73(52.90)$ & \\
\hline Never & 43 (30.94) & $70(50.72)$ & 0.001 & $37(26.62)$ & $65(47.10)$ & $4.09 \times 10^{-4}$ \\
\hline
\end{tabular}

Significant $P$-values in bold font.

*Pearson's chi-square test or the Fisher exact test for categorical variables and Student's $t$-test for continuous variables. All

$P$-values are two sided.

${ }^{* *}$ Pack year $=($ packs per day $) \times($ years smoked $)$.

\section{Development of a predictive miRNA panel containing 3 serum miRNA ratios}

Since there is no consensus on the standard method for normalization of data from circulating miRNA analysis, we also used the ratios between the expression values of all miRNAs as a quantification strategy, which has been identified as a robust and easily applicable method with potential for general application [14]. Each value of a single miRNA was compared with the values of all other remaining 52 miRNAs, and 1,378 ratios were obtained. A total of 147 miRNA ratios were significantly associated with risk of bladder cancer in the discovery set (Supplementary Table 2), and 6 of them remained significant in the validation set (Table 4). Among the latter group, half of the ratios were associated with decreased risk while the remaining ratios were associated with increased risk. The most significant protective effect between miRNA ratio and bladder cancer risk was observed in subjects with higher miR-409-3p/miR-423$5 \mathrm{p}$ ratio. These subjects displayed $50 \%$ lower risk for NMIBC (95\% CI 0.34-0.74) compared to those with low ratio. On the other hand, the most significant increased risk was found in subjects with high miR-29c-3p/miR-331-3p ratio, who showed 2-fold increased risk of NMIBC (95\% CI 1.34-3.03).
To determine a signature showing the best risk prediction, the combined effects of these serum miRNA ratios were investigated by incorporating their dichotomized status into our basic logistic regression model which included age, gender and smoking status. After testing a total of 63 possible combinations of the miRNA ratios, a signature of 3 miRNA ratios (miR-29a3p/miR-222-3p, miR-150-5p/miR-331-3p, miR-409-3p/ miR-423-5p) was able to improve the sensitivity and specificity for prediction of NMIBC risk over baseline model using epidemiologic variables of age, gender and smoking status in the combined set of subjects. A risk score based on the 3 miRNA ratio signature was calculated for all subjects. Patients with high-risk scores exhibited significantly increased risk of bladder cancer compared to those with low-risk scores (Discovery phase: $\mathrm{OR}=3.53,95 \% \mathrm{CI}: 1.59-7.83, P=1.89 \times 10^{-3}$; validation phase: $\mathrm{OR}=3.47,95 \% \mathrm{CI}: 1.68-7.19, P=7.86 \times 10^{-4}$; combined: $\mathrm{OR}=3.52,95 \% \mathrm{CI}: 2.06-6.00, P=3.78 \times$ $10^{-6}$ ) (Table 5).

\section{Association of serum 3-miRNA ratio panel with epidemiological factors in NMIBC risk}

To examine whether the effects of 3-miRNA ratio panel were modified by epidemiological factors, 


\begin{tabular}{|c|c|c|c|c|c|}
\hline Level & Cases, $N(\%)$ & Controls, $N(\%)$ & OR $^{*}(95 \%$ CI $)$ & $P$-value & $\boldsymbol{P}_{\text {heterogeneity }}$ \\
\hline \multicolumn{6}{|l|}{ Discovery } \\
\hline$>2.4$ & 38 (44.19) & $48(55.81)$ & \multicolumn{2}{|l|}{1 (reference) } & \\
\hline $0.46-2.4$ & $39(45.35)$ & $47(54.65)$ & $1.09(0.58-2.05)$ & 0.785 & \\
\hline$\leq 0.46$ & $54(62.07)$ & $33(37.93)$ & $2.32(1.20-4.49)$ & 0.012 & \\
\hline$P$ for trend & & & & 0.013 & \\
\hline \multicolumn{6}{|l|}{ Validation } \\
\hline$>2.4$ & $36(40.91)$ & $52(59.09)$ & \multicolumn{2}{|l|}{1 (reference) } & \\
\hline $0.46-2.4$ & $40(49.38)$ & $41(50.62)$ & $1.46(0.78-2.45)$ & 0.238 & \\
\hline$\leq 0.46$ & $46(58.97)$ & $32(41.03)$ & $2.19(1.14-4.22)$ & 0.019 & \\
\hline$P$ for trend & & & & 0.019 & \\
\hline \multicolumn{6}{|l|}{ Combined } \\
\hline$>2.4$ & 74 (42.29) & $101(57.71)$ & 1 (reference) & & \\
\hline $0.46-2.4$ & $87(54.04)$ & $74(45.96)$ & $1.30(0.84-2.03)$ & 0.242 & 0.520 \\
\hline$\leq 0.46$ & $83(58.87)$ & $58(41.13)$ & $2.21(1.40-3.50)$ & $7.19 \times 10^{-4}$ & 0.905 \\
\hline$P$ for trend & & & & $7.22 \times 10^{-4}$ & \\
\hline
\end{tabular}

Significant $P$-values in bold font.

*Adjusted by age, sex, smoking status and race.

we combined the discovery and validation set data and performed stratified analyses based on age and smoking status. As shown in Supplementary Table 3, consistent and significant association of high risk scores with NMIBC risk was observed regardless of age dichotomized at 65 years $(\leq 65$ years: $\mathrm{OR}=2.37,95 \% \mathrm{CI}: 1.30-4.31, P=4.74$ $\times 10^{-3} ;>65$ years: $\mathrm{OR}=2.66 ; 95 \% \mathrm{CI}=1.51-4.72, P=$ $7.65 \times 10^{-4}$ ) and smoking status (ever smokers: $\mathrm{OR}=3.45$; $95 \%$ CI: $1.82-6.54 ; P=7.02 \times 10^{-9}$; never smokers: OR $=2.90 ; 95 \%$ CI: $\left.1.45-5.81 ; P=2.60 \times 10^{-3}\right)$. These results further supported the possibility that our miRNA ratio panel was not simply a surrogate for known risk factors, but a novel biomarker for unexplained variance in NMIBC risk.

\section{Pathway enrichment analysis for serum miRNA signature}

To explore the possible biological pathways in which the serum miRNAs might be involved, pathway enrichment analysis was performed as described in
Materials and Methods. Target identification from miRsystem reported 1798 genes, and 245 genes showed observed-to-expected ratio greater than 1.5 suggesting less likelihood for chance finding. Among these 245 genes, we identified five genes (VEZF1, NFAT5, NFIX, PPARGC1A, and TNRC6B), each of which was targeted by four miRNAs in the 3-miRNA ratio panel. A custom dataset was created with these five target genes and six miRNAs in IPA. Core analysis was performed on the custom dataset, and we found one network containing three genes (VEZF1, PPARGC1A, TNRC6B) and five miRNAs (miR-150-5p, miR-222-3p, miR-331-3p, hsamiR-409-3p, miR-423-5p) from our custom dataset. We filtered out genes from the network, which were only linked to ubiquitin $\mathrm{C}$ gene, a universal degradation mechanism for multiple proteins. As shown in Figure 2, several miRNAs and their targets were linked to retinoid acid receptor (RAR) activation which involves $F O S$, PPARGC1A, SMAD2, VEGFA and tretinoin. Tretinoin is a retinoid suggested to possess chemopreventive activity via RAR signaling. 


\section{DISCUSSION}

In this study, we have focused on the role of miRNAs as potential diagnostic/risk prediction biomarkers of bladder cancer by conducting global and targeted miRNA profiling of serum samples. We discovered one miRNA miR-409-3p and six cancer-related miRNA ratios (miR-29a-3p/miR-222-3p, miR-29c-3p/miR-331-3p, miR-146a-5p/miR-423-5p, miR-150-5p/miR-331-3p, miR-331-3p/miR-423-5p and miR-409-3p/miR-423$5 p)$ were significantly associated with NMIBC risk in both discovery and validation groups. In addition miR409-3p and miR-342-3p were associated with early onset of NMIBC suggesting their roles in early cancer development. These miRNAs were highly detectable in sera from bladder cancer patients pointing to their utility

\section{Discovery}

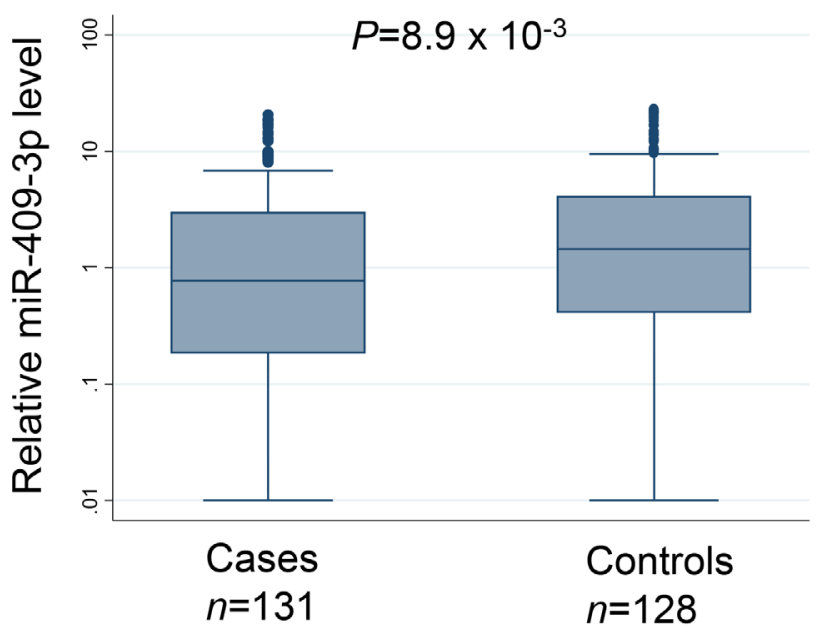

as noninvasive markers. We also developed a risk score by combining 3-miRNA ratios to distinguish NMIBC cases from controls. Once confirmed in independent studies, the miRNA panel may be applied to improve the discriminatory performance of bladder cancer risk prediction model incorporating host, clinical, and epidemiologic characteristics.

Although previous studies have reported serum miRNA expression profiles predicting cancer risk or outcome in several solid tumors [10,11, 14-16], studies focusing on the association of serum miRNA expression with bladder cancer were rather limited. Based on the qRT-PCR analysis of 22 selected miRNA candidates in 148 patients with NMIBC or muscle invasive bladder cancer and 115 control subjects, Scheffer AR et al. [17] failed to demonstrate a significant difference in serum

\section{Validation}

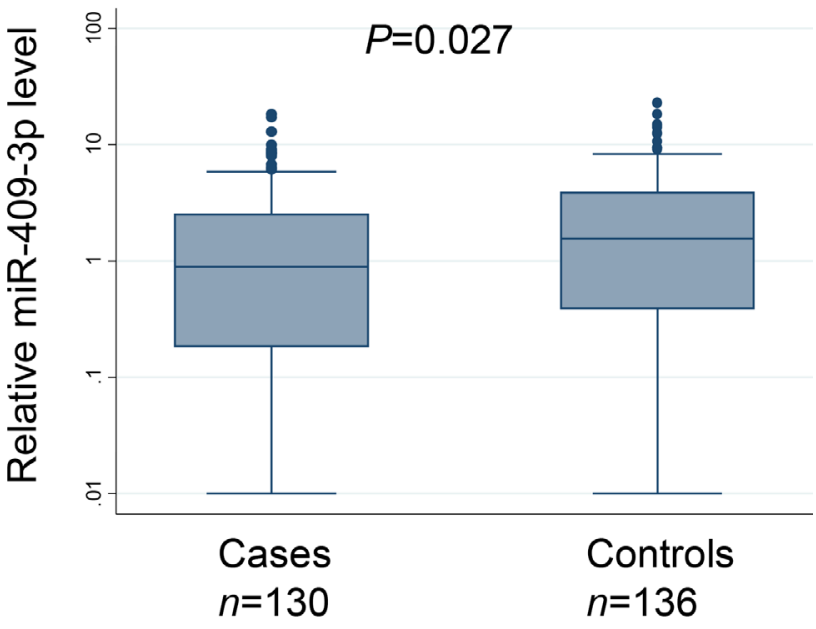

\section{Combined}

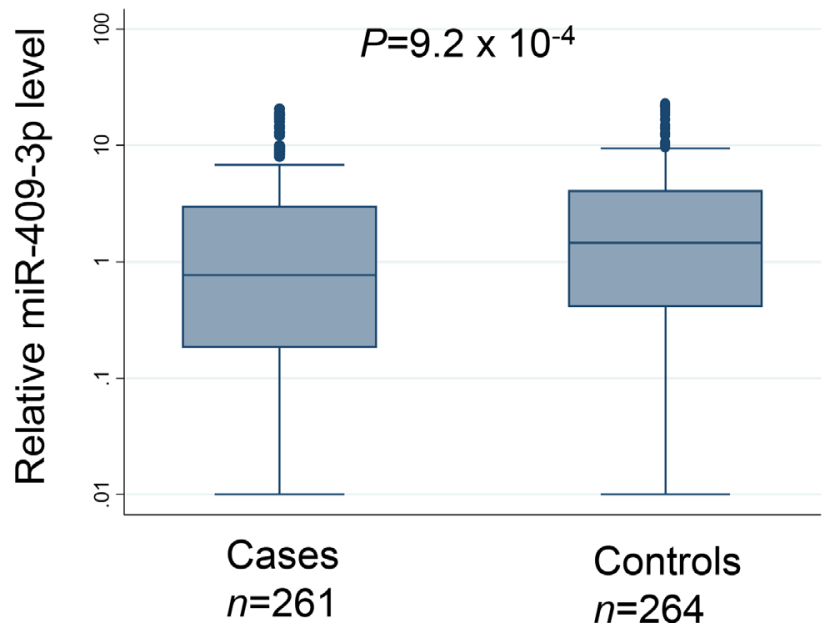

Figure 1: Box plots depicting relative serum expression level of miR-409-3p in NMIBC cases and controls in the discovery, validation, and combined sets. Line inside the box represents median value and the box denotes values from 25 th to 75 th percentile. Upper and lower bars represent $95 \%$ confidence interval. $P$-values were determined by Wilcoxon rank sum test. 
Table 3: Association of serum miRNAs with age of onset of NMIBC

\begin{tabular}{|c|c|c|c|c|c|c|c|c|c|c|c|c|}
\hline & \multicolumn{4}{|c|}{ Discovery } & \multicolumn{4}{|c|}{ Validation } & \multicolumn{4}{|c|}{ Combined } \\
\hline miRNA & $\begin{array}{l}\text { Cases } \\
\text { N (\%) }\end{array}$ & $\mathrm{HR}^{*}(95 \% \mathrm{CI})$ & $P$-value & $\begin{array}{c}\text { Median } \\
\text { age of } \\
\text { onset }\end{array}$ & $\begin{array}{c}\text { Cases } \\
(\%)\end{array}$ & $\mathrm{HR}^{*}(95 \% \mathrm{CI})$ & $P$-value & $\begin{array}{c}\text { Median } \\
\text { age of } \\
\text { onset }\end{array}$ & $\begin{array}{c}\text { Controls } \\
\text { N (\%) }\end{array}$ & $\mathrm{HR}^{*}(95 \% \mathrm{CI})$ & $P$-value & $\begin{array}{c}\text { Median } \\
\text { age of } \\
\text { onset }\end{array}$ \\
\hline \multicolumn{13}{|c|}{ miR409-3p } \\
\hline Low & $69(41.04)$ & 1 (reference) & & 68 & $62(45.07)$ & 1 (reference) & & 69 & $131(43.12)$ & 1 (reference) & & 68 \\
\hline High & $62(57.73)$ & $1.57(1.10-2.25)$ & 0.014 & 63 & $68(58.49)$ & $2.17(1.47-3.21)$ & $8.61 \times 10^{-5}$ & 61 & $130(58.13)$ & $1.83(1.41-2.38)$ & $2.02 \times 10^{-5}$ & 63 \\
\hline \multicolumn{13}{|c|}{$\operatorname{miR} 342-3 p$} \\
\hline Low & $55(57.89)$ & 1 (reference) & & 68 & $58(61.70)$ & 1 (reference) & & 68 & $136(59.79)$ & 1 (reference) & & 68 \\
\hline High & $55(45.08)$ & $1.81(1.26-2.60)$ & 0.008 & 61 & $57(42.86)$ & $1.45(1.02-2.06)$ & 0.039 & 64 & $135(43.92)$ & $1.60(1.24-2.05)$ & $2.05 \times 10^{-4}$ & 63 \\
\hline
\end{tabular}

"Adjusted by age, sex and smoking status.

Table 4: Association of serum miRNA ratios with risk of NMIBC

\begin{tabular}{|c|c|c|c|c|c|c|c|c|c|c|c|c|}
\hline \multirow[b]{2}{*}{ miRNA ratio } & \multicolumn{4}{|c|}{ Discovery } & \multicolumn{4}{|c|}{ Validation } & \multicolumn{4}{|c|}{ Combined } \\
\hline & $\begin{array}{l}\text { Cases } \\
N(\%)\end{array}$ & $\begin{array}{c}\text { Controls } \\
N(\%)\end{array}$ & $\mathrm{OR}^{*}(95 \% \mathrm{CI})$ & $P$-value & $\begin{array}{l}\text { Cases } \\
N(\%)\end{array}$ & $\begin{array}{c}\text { Controls } \\
N(\%)\end{array}$ & $\mathrm{OR}^{*}(95 \% \mathrm{CI})$ & $P$-value & $\begin{array}{c}\text { Cases } \\
N(\%)\end{array}$ & $\begin{array}{c}\text { Controls } \\
(\%)\end{array}$ & $\mathrm{OR}^{*}(95 \% \mathrm{CI})$ & $P$-value \\
\hline \multicolumn{13}{|l|}{$409-3 p / 423-5 p$} \\
\hline Low & $79(58.96)$ & $55(41.04)$ & 1 (reference) & & $78(54.93)$ & $64(45.07)$ & 1 (reference) & & $157(56.88)$ & $119(43.12)$ & 1 (reference) & \\
\hline High & $41(42.27)$ & $56(57.73)$ & $0.48(0.27-0.84)$ & 0.01 & $44(41.51)$ & $62(58.49)$ & $0.54(0.31-0.94)$ & 0.03 & 85 (41.87) & $118(58.13)$ & $0.50(0.34-0.74)$ & $<0.001$ \\
\hline \multicolumn{13}{|l|}{$29 c-3 p / 331-3 p$} \\
\hline Low & $40(42.11)$ & $55(57.89)$ & 1 (reference) & & $36(38.30)$ & $58(61.70)$ & 1 (reference) & & $76(40.21)$ & $113(59.79)$ & 1 (reference) & \\
\hline High & $67(54.92)$ & $55(45.08)$ & $1.80(1.00-3.22)$ & 0.048 & $76(57.14)$ & $57(42.86)$ & $2.34(1.31-4.16)$ & 0.004 & $143(56.08)$ & $112(43.92)$ & $2.02(1.34-3.03)$ & $<0.001$ \\
\hline \multicolumn{13}{|l|}{$331-3 p / 423-5 p$} \\
\hline Low & $70(59.32)$ & $48(40.68)$ & 1 (reference) & & $77(53.47)$ & $67(46.53)$ & 1 (reference) & & $147(56.11)$ & $115(43.89)$ & 1 (reference) & \\
\hline High & $43(42.57)$ & $58(57.43)$ & $0.43(0.24-0.77)$ & 0.004 & $41(41.84)$ & $57(58.16)$ & $0.55(0.31-0.97)$ & 0.039 & $84(42.21)$ & $115(57.79)$ & $0.51(0.34-0.75)$ & $<0.001$ \\
\hline \multicolumn{13}{|l|}{$29 a-3 p / 222-3 p$} \\
\hline Low & $43(40.95)$ & $62(59.05)$ & 1 (reference) & & $43(41.75)$ & $60(58.25)$ & 1 (reference) & & $86(41.35)$ & $122(58.65)$ & 1 (reference) & \\
\hline High & $78(59.09)$ & $54(40.91)$ & $1.97(1.13-3.42)$ & 0.016 & $84(55.63)$ & $67(44.37)$ & $1.85(1.09-3.14)$ & 0.023 & $162(57.24)$ & $121(42.76)$ & $1.90(1.30-2.78)$ & 0.001 \\
\hline \multicolumn{13}{|l|}{$146 a-5 p / 423-5 p$} \\
\hline Low & $71(57.26)$ & $53(42.74)$ & 1 (reference) & & $79(54.48)$ & $66(45.52)$ & 1 (reference) & & $150(55.76)$ & 119 (44.24) & 1 (reference) & \\
\hline High & $47(43.93)$ & $60(56.07)$ & $0.53(0.30-0.92)$ & 0.025 & $47(44.34)$ & $59(55.66)$ & $0.54(0.31-0.94)$ & 0.029 & $94(44.13)$ & $119(55.87)$ & $0.54(0.37-0.79)$ & 0.002 \\
\hline \multicolumn{13}{|l|}{$150-5 \mathrm{p} / 331-3 \mathrm{p}$} \\
\hline Low & $36(40.00)$ & $54(60.00)$ & 1 (reference) & & $48(40.68)$ & $70(59.32)$ & 1 (reference) & & $84(40.38)$ & $\begin{array}{c}124 \\
(59.62)\end{array}$ & 1 (reference) & \\
\hline High & $82(57.75)$ & $60(42.25)$ & $1.94(1.10-3.42)$ & 0.022 & $72(53.33)$ & $63(46.67)$ & $1.72(1.01-2.92)$ & 0.044 & $154(55.60)$ & $\begin{array}{c}123 \\
(44.40)\end{array}$ & $1.82(1.24-2.66)$ & 0.002 \\
\hline
\end{tabular}

miRNA levels between cases and controls. Because of the limited number of candidate miRNAs, small sample size and low detection rate of some miRNAs, it is possible that this study did not have sufficient statistical power to identify diagnostic biomarkers for bladder cancer. Another study was carried out in 44 cases across all stages and 34 controls in European population to validate 11 miRNAs associated with bladder cancer. The results suggested that miR-141 discriminates patients with bladder cancer with $70.5 \%$ sensitivity and $73.5 \%$ specificity [18]. In one recent publication, serum samples from Chinese subjects were screened with next-generation sequencing in 10 cases and 10 controls to identify differentially-expressed miRNAs. A total of 26 miRNAs were found significant and was used in subsequent training and validation profiling in 240 and 220 samples, respectively. Six miRNAs (miR-152, miR-148b-3p, miR-3187-3p, miR-15b-5p, miR-27a-3p and miR-30a-5p) were reported to be able to differentiate bladder cancer patients with an AUC of 0.899 [13]. In our study, we also detected and profiled miR-152, miR-148b, and miR-27a-3p; however, the results were not significant. To the best of our knowledge, this multi-phase study is 
Table 5: Association of serum 3-miRNA ratio panel risk score with NMIBC risk

\begin{tabular}{|c|c|c|c|c|c|}
\hline Sample set & Risk score & Cases, $N(\%)$ & Controls, $N(\%)$ & OR $^{*}(95 \% \mathrm{CI})$ & $P$-value \\
\hline \multirow[t]{4}{*}{ Discovery } & Low & $16(28.57)$ & $40(71.43)$ & \multicolumn{2}{|c|}{1 (reference) } \\
\hline & Medium & 47 (58.75) & $33(41.25)$ & $3.9(1.81-8.40)$ & $5.12 \times 10^{-4}$ \\
\hline & High & $37(58.73)$ & $26(41.27)$ & $3.53(1.59-7.83)$ & $1.89 \times 10^{-3}$ \\
\hline & Trend & & & & $2.82 \times 10^{-3}$ \\
\hline \multirow[t]{4}{*}{ Validation } & Low & $21(31.82)$ & $45(68.18)$ & \multicolumn{2}{|c|}{1 (reference) } \\
\hline & Medium & $40(49.38)$ & $41(50.62)$ & $2.25(1.10-4.61)$ & 0.027 \\
\hline & High & $46(58.97)$ & $32(41.03)$ & $3.47(1.68-7.19)$ & $7.86 \times 10^{-4}$ \\
\hline & Trend & & & & $8.71 \times 10^{-4}$ \\
\hline \multirow[t]{4}{*}{ Combined } & Low & $37(30.33)$ & 85 (69.67) & \multicolumn{2}{|c|}{1 (reference) } \\
\hline & Medium & $87(54.04)$ & $74(45.96)$ & $2.92(1.74-4.90)$ & $4.78 \times 10^{-5}$ \\
\hline & High & $83(58.87)$ & $58(41.13)$ & $3.52(2.06-6.00)$ & $3.78 \times 10^{-6}$ \\
\hline & Trend & & & & $6.49 \times 10^{-6}$ \\
\hline
\end{tabular}

Ratio panel consists of miR-29a-3p/miR-222-3p, miR-150-5p/miR-331-3p, and miR-409-3p/miR-423-5p.

${ }^{*}$ Adjusted by age, sex and smoking status.

the first to combine global and targeted miRNA profiling using Taqman miRNA arrays and Fluidigm's multiplex, high-throughput platform to analyze serum miRNAs associated with NMIBC in a Caucasian population.

In this study, we identified potential role of serum miR-409-3p, miR-342-3p, and a 3-miRNA ratio panel (miR-29a-3p/miR-222-3p, miR-150-5p/miR-331-3p, miR$409-3 \mathrm{p} / \mathrm{miR}-423-5 \mathrm{p}$ ) as risk predictors in NMIBC. The biological significance and association of these miRNAs with cancer have been previously reported. In particular, three miRNAs have been confirmed to be dysregulated in bladder cancer. MiR-409-3p was reported to inhibit migration and invasion of bladder cancer cells by targeting c-Met [19]. MiR-150-5p functions as a tumor promoter in reducing chemosensitivity and promoting invasiveness of muscle-invasive bladder cancer cells lines by targeting PDCD4 [20], while miR-222-3p overexpression in bladder cancer tissues is associated with poor prognosis possibly via suppression of $\mathrm{p} 27^{\mathrm{Kip} 1}$ [21]. The other three miRNAs, although not implicated in bladder cancer, have been shown to be associated with other types of cancers. Several targets have been biologically proven and linked to the roles of miR-29a-3p in various cancers. Indirect downregulation of matrix metalloproteinase 2 (MMP2) and E-cadherin by miR-29a-3p through Krüppel-like transcription factors 4 (KLF4) was reported in colon cancer cells [22]. Interestingly, KLF4 inhibition has been shown to promote invasion and migration in vitro [23] and linked to poor progression and early recurrence [24] in bladder cancer. In hepatocellular carcinoma, miR-29a-3p suppressed cell growth by inhibition of Secreted protein acidic and rich in cysteine (SPARC) [25] while SPARCdeficient mice were shown to develop urothelial carcinoma much earlier than mice expressing SPARC [26]. By targeting Lamin $\gamma 2$ (LAMC2), miR-29a-3p was reported to suppress migration and invasion in head and neck cancers [27], and overexpression of LAMC2 was found to enhance invasiveness in vivo [28]. In glioblastoma cells, miR-331-3p suppresses neuropilin-2 (NRP-2) expression directly [29], and NRP-2 has been reported to predict treatment response of bladder cancer [30]. MiR-331-3p has been shown to suppress ERBB2 signaling in prostate cancer [31] while ERBB-2 was indicated to be correlated with chemoradiation therapy resistance in muscle invasive bladder cancer patients [32]. In addition, E2F1 was a confirmed direct target of miR-331-3p in gastric cancer [33], and expression of $E 2 F 1$ and other associated genes were able to predict invasive progression of bladder cancer [34]. MiR-342 is a potential tumor suppressor and is known to be downregulated in several cancer types. For example, downregulation of miR-342 has been associated with tamoxifen resistant tumors [35]. MiR-342 was shown to be a negative regulator of E2F1 affecting MYC expression in lung cancer cells [36] and also negatively 
regulate FOXM1 and FOXQ1 expression in colorectal cancer cells [37]. Finally, miR-423-5p has been reported to be downregulated in gastric cancer [38] and a biomarker for colorectal cancer diagnosis [39]. Our results here provided evidence suggesting that these miRNAs might be involved in carcinogenesis of non-muscle invasive bladder cancer. Further study is required to clarify the role of these miRNAs in bladder cancer development.

Interestingly, we found the serum levels of miR-409$3 p$ and miR-342-3p inversely correlated with age, which contributed to its association with early onset of bladder cancer. Cases with higher expression of these miRNAs had earlier diagnosis of NMIBC compared to lower level group (by 5 years) even though the two miRNAs were protective in terms of risk. It should be noted the cases and controls were frequency-matched in terms of age and gender and that the median cutoff of serum miRNA level in the cases for age of onset analysis is lower than that of the case-control analysis using median cutoff for controls. Previous studies have implicated miR-409-3p to be involved in immune-regulatory function in natural killer and $\mathrm{T}$ cells $[40,41]$. It is possible that decreasing serum levels of this miRNA by age was due to decreased immune function during aging. More in depth mechanistic studies are needed to characterize the association. The relatively large sample size allowed us to examine how our miRNA panels performed in various age and smoking status strata. The elevated risks were consistent between age groups and when stratified by smoking status. Interaction between miRNA panel and age or miRNA panel and smoking was not significant $(P>0.05)$ suggesting independent association with NMIBC risk.

Delineation of the molecular pathways involved in bladder oncogenesis may expand the quest for muchneeded diagnostic biomarker discovery [42]. MiRNA target prediction tools coupled with the network analysis enabled us to determine pathways targeted by miRNA panels. In the network composed of our panel miRNAs and target genes, we found the miRNA panel could modulate the activation of RAR pathway involving

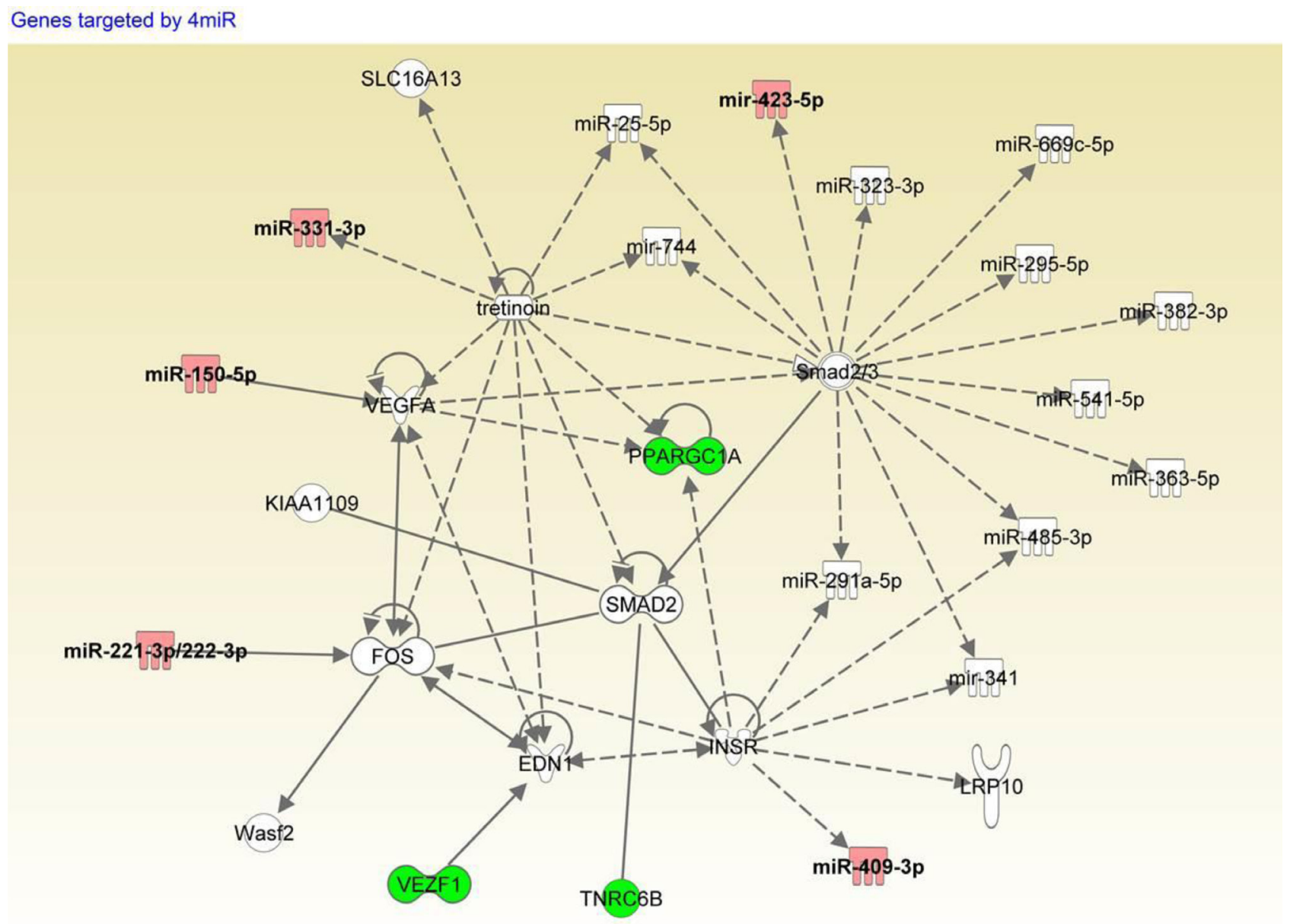

C) 2000-2015 QIAGEN. All rights reserved.

Figure 2: Integrative network analysis of 3-miRNA ratio combination panel and putative target genes. Panel consists of miR-29a-3p/miR-222-3p, miR-150-5p/miR-331-3p, and miR-409-3p/miR-423-5p. Red: microRNAs listed in the 3-miRNA ratio combination panel. Green: genes targeted by more than four miRNAs in the combination panel. 
retinoids. Retinoids are metabolites of vitamin A (retinol), and have been shown to bind the heterodimers of retinoic acid receptors (RARs) and/or retinoid $\mathrm{X}$ receptors (RXRs). The heterodimer of RAR and RXR binds to retinoic acid response elements (RAREs) and regulate downstream transcription via interaction with other coactivator and corepressors. Upon conjugation of retinoids, RAR/RXR dimers recruit more coactivators such as histone deacetyltransferases which are correlated with transcriptional activation of RAR target genes. Therefore, retinoic acid has been considered to be responsible for the activities of vitamin A [43]. Retinoids were found to inhibit cell cycle by upregulation of cellcycle inhibitors [44] and degradation of cyclin D1 [45]. They can also trigger apoptosis via induction of TNFrelated apoptosis-inducing ligand (TRAIL) signaling [46]. The epidemiological association between retinoids and bladder cancer were found back in 1979 [47]. Subsequent studies showed that dietary supplement containing a retinoid (all-trans-N-(4-hydroxyphenyl) retinamide (4HPR)) was able to decrease the depth of tumor invasion in a chemically-induced bladder cancer mouse model [48]. In 1985, de Bolla et al., reported that retinoid acid receptor expression was negatively correlated with recurrence [49]. The mechanisms behind these observations have not been fully clarified in bladder cancer, but transrepression of activator protein-1 (AP-1) which was composed of FOS and JUN by ligand-bound RAR/RXR complex has been suggested to account for the biological activity of retinoids in a mouse fibroblast cell line [50]. Inhibition of FOS has been reported to impact VEGFA protein level [51] and the downregulation of VEGFA could be linked to reduced PPARGC1A (PGC-1A) expression [52]. Based on prediction of target genes in miRsystem, miR-222-3p inhibits FOS, miR-150-5p inhibits VEGFA, and PPARGC1A is targeted by miR-150-5p, miR-409-3p and miR-222-3p. The involvement of our miRNA panels along the FOS-VEGFA-PPARGC1A axis suggests that the miRNAs might either serve as a proxy for the activation of RAR pathway, or a modulator of cellular response to retinoids. Besides miR-150 and miR-222, altered expression of these miRNAs in NMIBC tumor tissues have not been reported in literature [53]. Potential of these miRNA panels as a biomarker for tumor susceptibility warrants further investigation. In addition, VEGFA and INSR proteins in the above network have been under active investigation for targeted therapy [54]. Besides risk, the possibility of our miRNA panel to predict treatment response may warrant investigation to help refine personalized medicine.

Our study has several strengths including the multi-stage design with initial global screening of stably-expressed circulating miRNAs followed by targeted assessment in discovery and validation phases. Compared to most other studies of circulating miRNAs as risk predictors, the study is sufficiently powered for stratified analyses by covariate risk factors such as age and smoking status in order to detect biomarker interactions. We collected comprehensive epidemiologic and clinical information which are amenable for more integrative analysis. However, there are also some limitations including the relatively small sample size in one racial/ ethnic population to prevent broad generation, and the retrospective study design that allows the possibility for reverse causation. Additionally, the normalization of circulating miRNA expression and selection of internal controls are still challenging and ongoing research. Further studies are needed to determine the optimal reference miRNAs for qPCR analysis. Although we have maintained consistent quality control of our blood samples, variation in sample storage time and subject health conditions before blood collection might affect the measurement results. Nevertheless, some of these confounders would more likely bias towards the null.

In conclusion, using miRNA array profiling combined with Fluidigm platform, we provided evidence that serum miRNAs could potentially serve as noninvasive biomarkers for NMIBC. Further replication in independent prospective studies is warranted. The serum 3-miRNA ratio panel may contribute toward clinical application for noninvasive diagnosis, early detection or risk prediction of bladder cancer. Enrichment of target genes linked to RAR signaling provides biological plausibility regarding bladder cancer development and identifies novel candidates for therapeutic intervention.

\section{MATERIALS AND METHODS}

\section{Study population and epidemiological data}

This study included a total of 290 NMIBC cases and 288 healthy controls. Cases were recruited from The University of Texas MD Anderson Cancer Center and Baylor College of Medicine as a part of an ongoing bladder cancer case control study since 1999. As described previously [55], cases were all newly diagnosed, histologically confirmed, and previously untreated with chemotherapy or radiotherapy at the time of recruitment. Controls were healthy individuals without prior cancer history (except for non-melanoma skin cancer) and were recruited through Kelsey-Seybold Clinics, the largest multispecialty physician group in the Houston metropolitan area. Controls were frequency matched to cases on age ( \pm 5 years), sex and ethnicity. To control for population stratification, only Caucasians were included in this study as more than $90 \%$ of our recruited participants belonged to this group. All participants provided written informed consent before the collection of epidemiological data and blood samples.

Epidemiological data, including demographics, family history and smoking status, were collected by MD Anderson interviewers during a 45 min interview. 
Smoking status was classified as never-smokers (never smoked or smoked $<100$ cigarettes in their lifetime) and ever smokers (smoked $\geq 100$ cigarettes in their lifetime). Immediately after each interview, a $40 \mathrm{ml}$ peripheral blood sample was collected, of which about $10 \mathrm{ml}$ was drawn into a gold top serum-separating tube and processed for serum extraction within two hours. Extracted serum samples were then transferred to liquid nitrogen storage tanks until needed. All of the human study participation procedures were approved by the Institutional Review Boards at the University of Texas MD Anderson Cancer Center, the Baylor College of Medicine, and the Kelsey-Seybold Clinics.

\section{RNA isolation}

Isolation of total RNA from serum was carried out using miRNeasy Mini Kit (QIAGEN, Valencia, CA, USA) following the manufacturer's protocol. For each miRNA profiling and real-time PCR assay, $700 \mu \mathrm{L}$ serum was used. Single-stranded synthetic miRNA $(C$. elegans, cel-miR-39) was spiked into serum as a control for evaluation of successful extraction. RNAs were eluted twice with $30 \mu \mathrm{L}$ of water and stored at $-80^{\circ} \mathrm{C}$ until ready for use. RNA concentration was measured by NanoDrop ND-1000 spectrophotometer (Thermo Scientific, DE, USA). The RNA concentrations for all samples ranged from $42 \mathrm{ng} / \mu \mathrm{l}$ to $112 \mathrm{ng} / \mu \mathrm{l}($ mean $=80.4 \pm 17 \mathrm{ng} / \mu \mathrm{l})$. To ensure sufficient sample quality, the amount of serum and spike-in miRNAs prepared from the same batch were carefully kept consistent throughout all experiments. The effect of hemolysis during the serum preparation procedure [56] has been checked by detecting serum free hemoglobin level in the VITROS ${ }^{\circledR}$ Fusion 5.1 Chemistry System (Ortho Clinical Diagnostics) at the University of Texas MD Anderson Cancer Center Core Laboratory. All serum samples used for further analysis were free from significant hemolysis.

\section{MiRNA array profiling}

Global miRNA profiling was performed on serum samples from ten NMIBC patients and ten sex- and age-matched healthy subjects using TaqMan ${ }^{\circledR}$ Array Human MicroRNA Card Set v3.0 (Applied Biosystems, Foster City, CA, USA), which contains probes for 754 human miRNAs. Briefly, total circulating RNA was reverse-transcribed using TaqMan ${ }^{\circledR}$ MicroRNA Reverse Transcription Kit and the Megaplex ${ }^{\mathrm{TM}}$ RT Primers followed by a pre-amplification reaction using TaqMan ${ }^{\circledR}$ PreAmp Master Mix and Megaplex PreAmp Primers. Preamplified target cDNAs were then mixed with TaqMan $^{\circledR}$ Universal PCR Master Mix and loaded onto the TaqMan ${ }^{\circledR}$ MicroRNA Array. Quantitative real-time PCR was performed on the 7900HT Fast Real-Time PCR System (Applied Biosystems). Expression threshold for each miRNA detector was automatically determined. After initial screening, a total of 166 miRNAs could be detected. Among these, we selected 89 miRNAs that are related to cancer pathways or reported in bladder cancer based on literature [57-62] for further testing in discovery and validation sets (Supplementary Table 4). MiRNAs with a $\mathrm{Ct}$ value $<35$ and a missing rate $<25 \%$ in both study groups were considered as stably detectable candidates for further analysis.

\section{MiRNA expression by Fluidigm microfluidics dynamic arrays}

Selected miRNAs were measured using highthroughput BioMark ${ }^{\mathrm{TM}}$ HD Real-Time PCR system (Fluidigm, San Francisco, CA, USA). Reverse transcription and pre-amplification reaction were carried out using the same protocol as shown in miRNA array profiling, except primers for two spike-in miRNAs (celmiR-39 and cel-miR-54) were added. PCR Products were cleaned up using an enzymatic digestion approach by Exonuclease I (NEB, \#M0293L) to remove primers. After pre-amplification, a $5 \mu \mathrm{L}$ sample mixture was preparedcontaining $1 \times$ TaqMan Universal Master Mix (No UNG), $1 \times$ DNA sample Loading Reagent (Fluidigm) and each of pre-amplified cDNA. $5 \mu \mathrm{L}$ of assay mix was prepared with $1 \times$ each of TaqMan miRNA assay and 1 $\times$ Assay Loading Reagent (Fluidigm). The IFC controller HX (Fluidigm) was used to distribute the sample mix and assay mix from the loading inlets into the 96.96 Dynamic array reaction chambers. After loading, the chip was placed in the BioMark Instrument for real-time $\mathrm{PCR}$ at $95^{\circ} \mathrm{C}$ for $10 \mathrm{~min}$, followed by 40 cycles at $95^{\circ} \mathrm{C}$ for $15 \mathrm{sec}$ and $60^{\circ} \mathrm{C}$ for $1 \mathrm{~min}$. Data was analyzed with Real-Time PCR Analysis Software in the BIOMARK instrument (Fluidigm). Each PCR reaction was done in duplicate, including blank control, negative control and one calibrator DNA. The assay for cel-miR-39 was used for evaluation of RNA quality and for normalization in individual miRNA analysis; the assay for cel-miR-54 was used as negative control, and a calibrator DNA consisting of 10 random serum samples was used for comparison of results of different independent plate assays. Data that met one of the following criteria were excluded from further analysis: 1) the $\mathrm{Ct}$ value of duplicate assays differ from each for more than one cycle; 2) samples with a $\mathrm{Ct}$ value $>25$ or $<16$ in spike-in miRNAs; 3) miRNAs with a missing rate $>25 \%$; 4 ) data points outside 5 standard deviations were considered outliers and excluded from analysis. After data cleaning, 53 out of the 89 miRNA candidates were subjected to further analyses. For each miRNA obtained after data cleaning, the $\mathrm{Ct}$ value was normalized to the average expression of cel-miR-39 and then transformed to the corresponding expression value using the $2^{-\Delta \Delta \mathrm{Ct}}$ method. To generate miRNA ratios, the normalized mean $\mathrm{Ct}$ values were subjected to the $2^{-\Delta \Delta \mathrm{Ct}}$ 
method, and then one expression ratio was calculated for each pair of miRNAs.

\section{Pathway enrichment analysis}

Serum miRNA panels found to be significantly associated with bladder cancer were further analyzed by pathway enrichment analyses. We first identified genes targeted by the miRNA panel using miRsystem [63] which integrates results from seven prediction algorithms including DIANA [64], miRanda [65-67], mirBridge [68], PicTar [69], PITA [70], rna22 [71], and TargetScan [72-74], and two experimentally validated databases, TarBase [75] and miRecords [76]. Network enrichment was performed using QIAGEN's Ingenuity ${ }^{\circledR}$ Pathway Analysis (IPA ${ }^{\circledR}$, QIAGEN Redwood City, CA, USA; www.qiagen.com/ingenuity). Selected miRNAs and their target genes were entered to create a custom dataset for IPA core analysis. Networks enriched with most miRNAs and target genes were subjected to visual inspection. We removed the ubiquitin $\mathrm{C}$ (UBC)-related elements because UBC conjugation occurs commonly in the degradation of a broad spectrum of proteins without known significance in bladder cancer.

\section{Statistical analysis}

Statistical analyses were performed using Intercooled STATA version 10 (StataCorp, College Station, TX, USA). Pearson chi-square test (or the Fisher exact test, for categorical variables, sex, race and smoking status) or Student's $t$-test (for continuous variables, age) was used to evaluate differences in patient characteristics. Wilcoxon rank sum test was used to compare serum level of miRNAs in cases and controls. For analysis of individual miRNAs and their association with NMIBC risk, median and tertile levels of miRNAs in controls in the combined groups was used to categorize cases and controls. Odds ratios (ORs) and 95\% confidence intervals (CIs) were estimated using unconditional multivariable logistic regression analysis, adjusting for possible confounding by age, sex and smoking status. For analysis of individual miRNA association with age of onset of NMIBC, the median level in cases in the combined group was used to dichotomize miRNA level in the discovery and validation sets. Cox proportional hazard model adjusted for covariates was used to estimate association of miRNA level with age of onset. The ratios between two miRNA serum levels were generated using all possible combinations. The median miRNA ratio in the combined group was used to dichotomize miRNA ratios in the discovery and validation phases. Logistic regression was performed to determine the significance of each miRNA ratio as a predictor of NMIBC risk. Combinations of significant miRNA ratios were plugged into a multiple logistic regression model which included age, gender and smoking status. A single risk score comprised of the weighted sum for the 3 miRNA ratios were calculated and the weight is the adjusted $\log (\mathrm{OR})$ representing the estimated relative risk in log scale. The risk scores were dichotomized by the median of risk scores in controls of discovery phase. All $P$-values are two-sided, and $P$-value $\leq 0.05$ was considered statistically significant.

\section{Author contributions}

JL contributed to data acquisition, data analysis, and manuscript writing; SL was involved in data analysis and manuscript writing; YY and $\mathrm{MH}$ contributed to data analysis; DC contributed to data analysis and manuscript revision; CD provided the clinical resources; and XW was involved in project conception and design, data analysis, manuscript revision, and obtaining funding support.

\section{CONFLICTS OF INTEREST}

All authors declare no conflicts of interest.

\section{FUNDING AND GRANT SUPPORT}

This work was supported in part by grants from the National Institutes of Health/National Cancer Institute (P50 CA091846, U01 CA127615). Additional funding was provided by MD Anderson institutional support for the Center for Translational and Public Health Genomics, Duncan Family Institute for Cancer Prevention and Risk Assessment.

\section{REFERENCES}

1. Siegel RL, Miller KD, Jemal A. Cancer statistics, 2016. CA Cancer J Clin. 2016; 66:7-30.

2. Jacobs BL, Lee CT, Montie JE. Bladder cancer in 2010: how far have we come? CA Cancer J Clin. 2010; 60:244-272.

3. Goodison S, Rosser CJ, Urquidi V. Bladder cancer detection and monitoring: assessment of urine- and blood-based marker tests. Mol Diagn Ther. 2013; 17:71-84.

4. Cheung G, Sahai A, Billia M, Dasgupta P, Khan MS. Recent advances in the diagnosis and treatment of bladder cancer. BMC Med. 2013; 11:13.

5. Horstmann M, Patschan O, Hennenlotter J, Senger E, Feil G, Stenzl A. Combinations of urine-based tumour markers in bladder cancer surveillance. Scand J Urol Nephrol. 2009; 43:461-466.

6. Lieberman J, Slack F, Pandolfi PP, Chinnaiyan A, Agami R, Mendell JT. Noncoding RNAs and cancer. Cell. 2013; 153:9-10.

7. Yoshino H, Seki N, Itesako T, Chiyomaru T, Nakagawa M, Enokida H. Aberrant expression of microRNAs in bladder cancer. Nat Rev Urol. 2013; 10:396-404. 
8. Chen X, Ba Y, Ma L, Cai X, Yin Y, Wang K, Guo J, Zhang Y, Chen J, Guo X, Li Q, Li X, Wang W, et al. Characterization of microRNAs in serum: a novel class of biomarkers for diagnosis of cancer and other diseases. Cell Res. 2008; 18:997-1006.

9. Mitchell PS, Parkin RK, Kroh EM, Fritz BR, Wyman SK, Pogosova-Agadjanyan EL, Peterson A, Noteboom J, O'Briant KC, Allen A, Lin DW, Urban N, Drescher CW, et al. Circulating microRNAs as stable blood-based markers for cancer detection. Proc Natl Acad Sci USA. 2008; 105:10513-10518.

10. Toiyama Y, Takahashi M, Hur K, Nagasaka T, Tanaka K, Inoue Y, Kusunoki M, Boland CR, Goel A. Serum miR-21 as a diagnostic and prognostic biomarker in colorectal cancer. J Natl Cancer Inst. 2013; 105:849-859.

11. Zhou J, Yu L, Gao X, Hu J, Wang J, Dai Z, Wang JF, Zhang Z, Lu S, Huang X, Wang Z, Qiu S, Wang X, et al. Plasma microRNA panel to diagnose hepatitis B virusrelated hepatocellular carcinoma. J Clin Oncol. 2011; 29:4781-4788.

12. Alhasan AH, Scott AW, Wu JJ, Feng G, Meeks JJ, Thaxton $\mathrm{CS}$, Mirkin CA. Circulating microRNA signature for the diagnosis of very high-risk prostate cancer. Proc Natl Acad Sci USA. 2016; 113:10655-10660.

13. Jiang X, Du L, Wang L, Li J, Liu Y, Zheng G, Qu A, Zhang $\mathrm{X}$, Pan H, Yang Y, Wang C. Serum microRNA expression signatures identified from genome-wide microRNA profiling serve as novel noninvasive biomarkers for diagnosis and recurrence of bladder cancer. Int J Cancer. 2015; 136:854-862.

14. Boeri M, Verri C, Conte D, Roz L, Modena P, Facchinetti F, Calabro E, Croce CM, Pastorino U, Sozzi G. MicroRNA signatures in tissues and plasma predict development and prognosis of computed tomography detected lung cancer. Proc Natl Acad Sci USA. 2011; 108:3713-3718.

15. Li A, Yu J, Kim H, Wolfgang CL, Canto MI, Hruban RH, Goggins M. MicroRNA array analysis finds elevated serum miR-1290 accurately distinguishes patients with low-stage pancreatic cancer from healthy and disease controls. Clin Cancer Res. 2013; 19:3600-3610.

16. Hu Z, Chen X, Zhao Y, Tian T, Jin G, Shu Y, Chen Y, Xu L, Zen K, Zhang C, Shen H. Serum microRNA signatures identified in a genome-wide serum microRNA expression profiling predict survival of non-small-cell lung cancer. $\mathrm{J}$ Clin Oncol. 2010; 28:1721-1726.

17. Scheffer AR, Holdenrieder S, Kristiansen G, von Ruecker A, Muller SC, Ellinger J. Circulating microRNAs in serum: novel biomarkers for patients with bladder cancer? World J Urol. 2014; 32:353-58.

18. Kriebel S, Schmidt D, Holdenrieder S, Goltz D, Kristiansen G, Moritz R, Fisang C, Müller SC, Ellinger J. Analysis of tissue and serum microRNA expression in patients with upper urinary tract urothelial cancer. PLoS One. 2015; 10:e0117284.

19. Xu X, Chen H, Lin Y, Hu Z, Mao Y, Wu J, Xu X, Zhu Y, Li S, Zheng X, Xie L. MicroRNA-409-3p inhibits migration and invasion of bladder cancer cells via targeting c-Met. Mol Cells. 2013; 36:62-68.

20. Lei Y, Hu X, Li B, Peng M, Tong S, Zu X, Wang Z, Qi L, Chen M. miR-150 modulates cisplatin chemosensitivity and invasiveness of muscle-invasive bladder cancer cells via targeting PDCD4 in vitro. Med Sci Monit. 2014; 20:1850-1857.

21. Zhang DQ, Zhou CK, Jiang XW, Chen J, Shi BK. Increased expression of miR-222 is associated with poor prognosis in bladder cancer. World J Surg Oncol. 2014; 12:241.

22. Tang W, Zhu Y, Gao J, Fu J, Liu C, Liu Y, Song C, Zhu S, Leng Y, Wang G, Chen W, Du P, Huang S, et al. MicroRNA29a promotes colorectal cancer metastasis by regulating matrix metalloproteinase 2 and E-cadherin via KLF4. Br J Cancer. 2014; 110:450-58.

23. Xiao H, Li H, Yu G, Xiao W, Hu J, Tang K, Zeng J, He W, Zeng G, Ye Z, Xu H. MicroRNA-10b promotes migration and invasion through KLF4 and HOXD10 in human bladder cancer. Oncol Rep. 2014; 31:1832-38.

24. Li H, Wang J, Xiao W, Xia D, Lang B, Wang T, Guo X, $\mathrm{Hu} \mathrm{Z}, \mathrm{Ye} \mathrm{Z}, \mathrm{Xu} \mathrm{H}$. Epigenetic inactivation of KLF4 is associated with urothelial cancer progression and early recurrence. J Urol. 2014; 191:493-501.

25. Zhu XC, Dong QZ, Zhang XF, Deng B, Jia HL, Ye QH, Qin LX, Wu XZ. microRNA-29a suppresses cell proliferation by targeting SPARC in hepatocellular carcinoma. Int J Mol Med. 2012; 30:1321-26.

26. Said N, Frierson HF, Sanchez-Carbayo M, Brekken RA, Theodorescu D. Loss of SPARC in bladder cancer enhances carcinogenesis and progression. J Clin Invest. 2013; 123:751-66.

27. Kinoshita $T$, Nohata $N$, Hanazawa $T$, Kikkawa $N$, Yamamoto $\mathrm{N}$, Yoshino $\mathrm{H}$, Itesako $\mathrm{T}$, Enokida $\mathrm{H}$, Nakagawa M, Okamoto Y, Seki N. Tumour-suppressive microRNA-29s inhibit cancer cell migration and invasion by targetin $\mathrm{g}$ laminin-integrin signalling in head and neck squamous cell carcinoma. Br J Cancer. 2013; 109:2636-45.

28. Tsubota Y, Ogawa T, Oyanagi J, Nagashima Y, Miyazaki K. Expression of laminin gamma2 chain monomer enhances invasive growth of human carcinoma cells in vivo. Int $\mathrm{J}$ Cancer. 2010; 127:2031-41.

29. Epis MR, Giles KM, Candy PA, Webster RJ, Leedman PJ. miR-331-3p regulates expression of neuropilin-2 in glioblastoma. J Neurooncol. 2014; 116:67-75.

30. Keck B, Wach S, Taubert H, Zeiler S, Ott OJ, Kunath F, Hartmann A, Bertz S, Weiss C, Honscheid P, Schellenburg S, Rodel C, Baretton GB, et al. Neuropilin-2 and its ligand VEGF-C predict treatment response after transurethral 
resection and radiochemotherapy in bladder cancer patients. Int J Cancer. 2015 Jan 15;136:443-51.

31. Epis MR, Giles KM, Barker A, Kendrick TS, Leedman PJ. miR-331-3p regulates ERBB-2 expression and androgen receptor signaling in prostate cancer. J Biol Chem. 2009; 284:24696-704.

32. Inoue M, Koga F, Yoshida S, Tamura T, Fujii Y, Ito E, Kihara K. Significance of ERBB2 overexpression in therapeutic resistance and cancer-specific survival in muscle-invasive bladder cancer patients treated with chemoradiation-based selective bladder-sparing approach. Int J Radiat Oncol Biol Phys. 2014; 90:303-11.

33. Guo X, Guo L, Ji J, Zhang J, Zhang J, Chen X, Cai Q, Li J, Gu Q, Liu B, Zhu Z, Yu Y. miRNA-331-3p directly targets E2F1 and induces growth arrest in human gastric cancer. . Biochem Biophys Res Commun. 2010; 398:1-6.

34. Lee JS, Leem SH, Lee SY, Kim SC, Park ES, Kim SB, Kim SK, Kim YJ, Kim WJ, Chu IS. Expression signature of E2F1 and its associated genes predict superficial to invasive progression of bladder tumors. J Clin Oncol. 2010; 28:2660-67.

35. Cittelly DM, Das PM, Spoelstra NS, Edgerton SM, Richer JK, Thor AD, Jones FE. Down regulation of miR-342 is associated with tamoxifen breast tumors. Mol Cancer. 2010; 20:9:317.

36. Tai MC, Kajino T, Nakatochi M, Arima C, Shimada Y, Suzuki M, Miyoshi H, Yatabe Y, Yanagisawa K, Takahashi T. miR-342-3p regulates MYC transcriptional activity via direct repression of $\mathrm{E} 2 \mathrm{~F} 1$ in human lung cancer. Carcinogenesis. 2015; 36:1464-73.

37. Weng W, Okugawa Y, Toden S, Toiyama Y, Kusunoki M, Goel A. FOXM1 and FOXQ1 are promising prognostic biomarkers and novel targets of tumor suppressive miR342 in human colorectal cancer. Clin Cancer Res. 2016; 22:4947-4957.

38. Dong L, Deng J, Sun ZM, Pan AP, Xiang XJ, Zhang L, Yu F, Chen J, Sun Z, Feng M, Xiong JP. Interference with the beta-catenin gene in gastric cancer induces changes to the miRNA expression profile. Tumour Biol. 2015; 36:6973-6983.

39. $\mathrm{Lu} \mathrm{X}, \mathrm{Lu}$ J. The significance of detection of serum miR423-5p and miR-484 for diagnosis of colorectal cancer. Clin Lab. 2015; 61:187-190.

40. Himmelreich $\mathrm{H}$, Mathys A, Wodnar-Filipowicz A, Kalberer CP. Post-transcriptional regulation of ULBP1 ligand for the activating immunoreceptor NKG2D involves 3' untranslated region. Hum Immunol. 2011; 72:470-478.

41. Eichmüller SB, Osen W, Mandelboim O, Seliger B. Immune Modulatory microRNAs Involved in Tumor Attack and Tumor Immune Escape. J Natl Cancer Inst. 2017; 109.

42. Netto GJ. Molecular biomarkers in urothelial carcinoma of the bladder: are we there yet? Nat Rev Urol. 2011; 9:41-51.

43. Chambon P. A decade of molecular biology of retinoic acid receptors. FASEB J. 1996; 10:940-954.
44. Luo P, Lin M, Lin M, Chen Y, Yang B, He Q. Function of retinoid acid receptor alpha and p21 in all-trans-retinoic acid-induced acute T-lymphoblastic leukemia apoptosis. Leuk Lymphoma. 2009; 50:1183-1189.

45. Ma Y, Feng Q, Sekula D, Diehl JA, Freemantle SJ, Dmitrovsky E. Retinoid targeting of different D-type cyclins through distinct chemopreventive mechanisms. Cancer Res. 2005; 65:6476-6483.

46. Altucci L, Leibowitz MD, Ogilvie KM, de Lera AR, Gronemeyer H. RAR, RXR modulation in cancer and metabolic disease. Nat Rev Drug Discov. 2007; 6:793-810.

47. Mettlin C, Graham S. Dietary risk factors in human bladder cancer. Am J Epidemiol. 1979; 110:255-263.

48. Moon RC, Kelloff GJ, Detrisac CJ, Steele VE, Thomas $\mathrm{CF}$, Sigman CC. Chemoprevention of $\mathrm{OH}-\mathrm{BBN}$-induced bladder cancer in mice by oltipraz, alone and in combination with 4-HPR and DFMO. Anticancer Res. 1994; 14:5-11.

49. de Bolla AR, Shave RM, Fagg SL, Heald K, Hughes MA, Wallace DM, Edwards PD. The influence of retinoic acid receptor (RAR) status of bladder tumours on the course of the disease. Br J Urol. 1985; 57:676-679.

50. Chen JY, Penco S, Ostrowski J, Balaguer P, Pons M, Starrett JE, Reczek P, Chambon P, Gronemeyer H. RAR-specific agonist/antagonists which dissociate transactivation and AP1 transrepression inhibit anchorage-independent cell proliferation. EMBO J. 1995; 14:1187-1197.

51. Sun K, Wernstedt Asterholm I, Kusminski CM, Bueno AC, Wang ZV, Pollard JW, Brekken RA, Scherer PE. Dichotomous effects of VEGF-A on adipose tissue dysfunction. Proc Natl Acad Sci USA. 2012; 109:5874-79.

52. Arany Z, Foo SY, Ma Y, Ruas JL, Bommi-Reddy A, Girnun G, Cooper M, Laznik D, Chinsomboon J, Rangwala SM, Baek KH, Rosenzweig A, Spiegelman BM. HIFindependent regulation of VEGF and angiogenesis by the transcriptional coactivator PGC-1alpha. Nature. 2008; 451:1008-1012.

53. Amir S, Mabjeesh NJ. microRNA expression profiles as decision-making biomarkers in the management of bladder cancer. Histol Histopathol. 2017; 32:107-119.

54. Rask-Andersen M, Masuram S, Schioth HB. The druggable genome: Evaluation of drug targets in clinical trials suggests major shifts in molecular class and indication. Annu Rev Pharmacol Toxicol. 2014; 54:9-26.

55. Lee EK, Ye Y, Kamat AM, Wu X. Genetic variations in regulator of G-protein signaling (RGS) confer risk of bladder cancer. Cancer. 2013; 119:1643-1651.

56. Wang Y, Gu J, Roth JA, Hildebrandt MA, Lippman SM, Ye Y, Minna JD, Wu X. Pathway-based serum microRNA profiling and survival in patients with advanced stage nonsmall cell lung cancer. Cancer Res. 2013; 73:4801-4809.

57. Adam L, Wszolek MF, Liu CG, Jing W, Diao L, Zien A, Zhang JD, Jackson D, Dinney CP. Plasma microRNA profiles for bladder cancer detection. Urol Oncol. 2013; 31:1701-1708. 
58. Wang P, Zhuang L, Zhang J, Fan J, Luo J, Chen H, Wang K, Liu L, Chen Z, Meng Z. The serum miR-21 level serves as a predictor for the chemosensitivity of advanced pancreatic cancer, and miR-21 expression confers chemoresistance by targeting FasL. Mol Oncol. 2013; 7:334-345.

59. Asaga S, Kuo C, Nguyen T, Terpenning M, Giuliano AE, Hoon DS. Direct serum assay for microRNA-21 concentrations in early and advanced breast cancer. Clin Chem. 2011; 57:84-91.

60. Snowdon J, Boag S, Feilotter H, Izard J, Siemens DRJ. A pilot study of urinary microRNA as a biomarker for urothelial cancer. Can Urol Assoc J. 2013; 7:28-32.

61. Wang G, Chan ES, Kwan BC, Li PK, Yip SK, Szeto CC, Ng CF. Expression of microRNAs in the urine of patients with bladder cancer. Clin Genitourin Cancer. 2012;10:106-113.

62. Puerta-Gil P, García-Baquero R, Jia AY, Ocaña S, AlvarezMúgica M, Alvarez-Ossorio JL, Cordon-Cardo C, Cava F, Sánchez-Carbayo M. miR-143, miR-222, and miR-452 are useful as tumor stratification and noninvasive diagnostic biomarkers for bladder cancer. Am J Pathol. 2012; 180:1808-1815.

63. Lu TP, Lee CY, Tsai MH, Chiu YC, Hsiao CK, Lai LC, Chuang EY. miRSystem: an integrated system for characterizing enriched functions and pathways of microRNA targets. PLoS One. 2012; 7:e42390.

64. Maragkakis M, Alexiou P, Papadopoulos GL, Reczko M, Dalamagas T, Giannopoulos G, Goumas G, Koukis E, Kourtis K, Simossis VA, Sethupathy P, Vergoulis T, Koziris $\mathrm{N}$, et al. Accurate microRNA target prediction correlates with protein repression levels. BMC Bioinformatics. 2009; 10:295.

65. John B, Enright AJ, Aravin A, Tuschl T, Sander C, Marks DS. Human MicroRNA targets. PLoS Biol. 2004; 2:e363.

66. Enright AJ, John B, Gaul U, Tuschl T, Sander C, Marks DS. MicroRNA targets in Drosophila. Genome Biol. 2003; 5:R1.
67. Betel D, Wilson M, Gabow A, Marks DS, Sander C. The microRNA.org resource: targets and expression. Nucleic Acids Res. 2008; 36:D149-153.

68. Tsang JS, Ebert MS, van Oudenaarden A. Genome-wide dissection of microRNA functions and cotargeting networks using gene set signatures. Mol Cell. 2010; 38:140-153.

69. Krek A, Grün D, Poy MN, Wolf R, Rosenberg L, Epstein EJ, MacMenamin P, da Piedade I, Gunsalus KC, Stoffel M, Rajewsky N. Combinatorial microRNA target predictions. Nat Genet. 2005; 37:495-500.

70. Kertesz M, Iovino N, Unnerstall U, Gaul U, Segal E. The role of site accessibility in microRNA target recognition. Nat Genet. 2007; 39:1278-84.

71. Miranda KC, Huynh T, Tay Y, Ang YS, Tam WL, Thomson AM, Lim B, Rigoutsos I. A pattern-based method for the identification of MicroRNA binding sites and their corresponding heteroduplexes. Cell. 2006; 126:1203-1217.

72. Lewis BP, Burge CB, Bartel DP. Conserved seed pairing, often flanked by adenosines, indicates that thousands of human genes are microRNA targets. Cell. 2005; 120:15-20.

73. Grimson A, Farh KK, Johnston WK, Garrett-Engele P, Lim LP, Bartel DP. MicroRNA targeting specificity in mammals: determinants beyond seed pairing. Mol Cell. 2007; 27:91-105.

74. Friedman RC, Farh KK, Burge CB, Bartel DP. Most mammalian mRNAs are conserved targets of microRNAs. Genome Res. 2009; 19:92-105.

75. Papadopoulos GL, Reczko M, Simossis VA, Sethupathy P, Hatzigeorgiou AG. The database of experimentally supported targets: a functional update of TarBase. Nucleic Acids Res. 2009; 37:D155-158.

76. Xiao F, Zuo Z, Cai G, Kang S, Gao X, Li T. miRecords: an integrated resource for microRNA-target interactions. Nucleic Acids Res. 2009; 37:D105-110. 